(c) American Dairy Science Association, 2003.

\title{
Characterization and Genotyping of the Caprine $\kappa$-Casein Variants
}

\author{
M. H. Yahyaoui, ${ }^{*}$ A. Angiolillo,† F. Pilla,† A. Sanchez, ${ }^{*}$ and J. M. Folch* \\ *Departament de Ciència Animal i del Aliments, Facultat de Veterinària, \\ Universitat Autònoma de Barcelona, 08193 Bellaterra, Spain \\ †Dipartimento S.A.V.A, Universitá del Molise, Campobasso, Italy
}

\begin{abstract}
$\kappa$-Casein $(\kappa$-CN) is the milk protein that determines the size and specific function of milk micelles, and its cleavage by chymosin is responsible for milk coagulation. We have previously detected and characterized four variants of the goat $\kappa$-CN in Spanish, French, and Italian breeds by screening the major part of the coding region in exon 4 . Here we have sequenced and analyzed the full coding region of the $\kappa$-CN gene which includes exons 3 and 4 . No additional mutations were found, with exception of a single nucleotide substitution in exon 3, which had no amino acid change. However, the analysis of the association between the different mutations resulted in two new variants designated $\kappa$ $\mathrm{CN} \mathrm{F}$ and G. The novel variants are present in the Italian breeds Teramana, Girgentana, and Sarda (variant F). A protocol for rapid simultaneous genotyping of all known $\kappa$-CN variants using the primer extension method was described, and a total of 210 animals from nine European breeds were genotyped. Alleles A and $B$ are the most frequent variants occuring in the majority of breeds with highest prevalence of the B variant, except for the Canaria breed where the A allele is more frequent. Sequence data suggest that the $\mathrm{F}$ variant is the original type of caprine $\kappa$-CN, other alleles being derived from this type following two different trunks by successive mutations.
\end{abstract}

(Key words: genetic polymorphism, genotyping, goat, $\kappa$-casein)

Abbreviation key: PEA = primer extension analysis, $\mathbf{R F L P}=$ restriction fragment length polymorphism.

\section{INTRODUCTION}

$\kappa$-Casein is the protein in milk that allows the formation and stabilization of milk micelles and determines their size and function (Gutiérrez et al., 1996). It differs from other caseins in its solubility over a broad range

Received December 3, 2002.

Accepted March 13, 2003.

Corresponding author: M. Habib Yahyaoui; e-mail: Habib. Yahyaoui@uab.es. of calcium ion concentrations and contains a hydrophilic C-terminal region. Besides these characteristics, the mature $\kappa$-CN protein has a labile peptide bond whose cleavage by chymosin (or rennin) produces a soluble hydrophilic glycopeptide (caseino-macropeptide) as well as an insoluble peptide or para- $\kappa-\mathrm{CN}$. The caseino-macropeptide is responsible for milk coagulation while the function of the para- $\kappa-\mathrm{CN}$ is not well known. The study of genetic polymorphisms of the caseins is of interest, since some variants could be more beneficial from the point of view of human nutrition (Boland et al., 2001) or be associated with milk quality, composition and technological characteristics. In sheep, the $\kappa$ CN is considered to be monomorphic (revised in Moioli et al., 1998) whereas bovine $\kappa$-CN has six variants with $\mathrm{A}$ and $\mathrm{B}$ being the most common variants (revised in Kaminski, 1996). The milk of cows carrying the B allele of $\kappa$-CN contains a smaller and more homogeneous micelle size (Schaar, 1984), with an elevated concentration of $\kappa$-CN in milk resulting in higher cheese yield (revised in Ng-Kwai Hang, 1998).

The caprine $\kappa$-CN protein contains 171 amino acid residues (Mercier et al., 1976a; 1976b) and the nucleotide sequence of the cDNA and the promoter region of the gene have been reported (Coll et al., 1993; 1995). The caprine $\kappa$-CN gene comprises five exons with the coding region for mature protein contained in exons 3 (9 amino acids) and 4 (162 amino acids). We have previously detected and characterized three variants of the goat $\kappa$-CN gene (designated A, B, and C) in Spanish and French breeds, and reported the frequency of the $\mathrm{C}$ allele (Yahyaoui et al., 2001). The analyzed region (459 bp of exon 4) contains the major part of the coding sequence for mature protein (141 amino acids over a total of 171). Two other variants present in German and Italian goat breeds have been reported recently (Caroli et al., 2001; Angiolillo et al., 2002).

Due to the confusion now present in the literature caused by assigning the same name to different variants, it is necessary to clearly define the different alleles and develop methods for their rapid discrimination. The aim of this work was to describe a method for rapid and cost efficient genotyping of all known caprine $\kappa$ $\mathrm{CN}$ variants. A nomenclature for the different alleles 
is proposed. In addition, we analyzed the full coding region of the $\kappa$-CN gene and report two new genetic variants as well as the allele distribution among different European goat breeds.

\section{MATERIALS AND METHODS}

\section{Animal Samples}

A total of 210 animals belonging to different Spanish (Murciano-Granadina $\mathrm{n}=30$, Canaria $\mathrm{n}=30$, Malagueña $n=11$ ), Italian (Teramana $n=28$, Montefalcone $\mathrm{n}=17$, Girgentana $\mathrm{n}=19$, Sarda $\mathrm{n}=19$ ) and French (Alpine $n=28$, Saanen $n=28$ ) goat breeds were analyzed. In addition, 23 DNA samples from the Spanish wild goat (Capra pyrenaica sp. hispanica) were included in the study. DNA was extracted from blood samples using a standard procedure (Ausubel et al., 1987).

\section{Amplification of the Caprine $\kappa$-CN Gene}

For the amplification of the DNA region encoding the mature $\kappa$-CN protein, two sets of primers were used: I2F (5'-ATG TAT CTG TCA TTT CTT GAG GTT TC$\left.3^{\prime}\right)$ - I3R2 (5'-CTC ATG AAA ATC AAC ACA ACT TAG CC-3') for exon 3 amplification (469 bp) and I3F (5'TCC CAA TGT TGT ACT TTC TTA ACA TC-3') - Kb2 (5'-GCG TTG TCC TCT TTG ATG TCT CCT TAG-3') for amplification of exon 4 (645 bp). Primers I2F, I3F, and I3R2 were designed over sequenced introns 2 and 3 of the caprine $\kappa$-CN gene (unpublished data) while $\mathrm{Kb} 2$ was designed relative to the caprine $\kappa$ - $\mathrm{CN}$ cDNA (Coll et al., 1993). The PCR reaction was performed in a $25-\mu$ l final volume containing 0.625 unit of Taq DNA polymerase (Life Technologies, Rockville, MD), $1 \times$ PCR buffer, $1.5 \mathrm{~m} M \mathrm{MgCl}_{2}, 200 \mu M$ each dNTP, $0.4 \mu M$ each primer and approximately $100 \mathrm{ng}$ of goat genomic DNA. Thermal cycling conditions were: $95^{\circ} \mathrm{C}$ for $5 \mathrm{~min}, 10$ cycles of $97^{\circ} \mathrm{C}$ for $15 \mathrm{~s}, 63^{\circ} \mathrm{C}$ for $1 \mathrm{~min}$ and $72^{\circ} \mathrm{C}$ for 1 min $30 \mathrm{~s}$, followed by 25 cycles of $95^{\circ} \mathrm{C}$ for $30 \mathrm{~s}, 63^{\circ} \mathrm{C}$ for $1 \mathrm{~min}$ and $72^{\circ} \mathrm{C}$ for $1 \mathrm{~min} 30 \mathrm{~s}$, with a final extension at $72^{\circ} \mathrm{C}$ for $5 \mathrm{~min}$.

\section{DNA Sequencing Reactions}

A total of 16 PCR products from different breeds (Murciano-Granadina, Girgentana, Saanen, and Teramana) were sequenced for exon 3 using a nested primer I3R1 (5'-GAT TCA TAC GAT TGG ATG AAA TG-3') and for exon 4 with primers I3F and $\mathrm{Kb} 2$. In addition, three DNA samples from the Spanish wild goat was sequenced for exon 4 . In order to establish haplotypes, five DNA samples from Teramana and Murciano-Granadina breeds were amplified (exon 4) with Expand High Fidelity PCR System (Roche Molecular Diagno- sys, Indianapolis, IN), purified with Concert kit (Life Technologies) and cloned using TOPO-TA cloning kit (Invitrogen, Carlsbad, CA). Two clones per sample were sequenced by the dideoxy method using forward and reverse M13 primers and an ABI Prism 310 automated DNA sequencer (Perkin Elmer). Nucleotide sequences were analyzed by Multialin software (Corpet, 1988).

\section{Single Nucleotide Primer Extension Analysis}

All animal samples (210 goats from different breeds and 23 Spanish wild goats) were genotyped for the $\kappa$ $\mathrm{CN}$ variants by the primer extension analysis method using the Multiplex SNaPshot ddNTP kit (PE Applied Biosystems, Foster City, CA). The assay utilizes internal unlabeled primer which binds to a complementary PCR-generated template in the presence of AmpliTaq DNA Polymerase and fluorescently labeled ddNTPs. The polymerase extends the primer one nucleotide, adding a single ddNTP to its $3^{\prime}$ end. Primers were designed to allow size- and color-discrimination between the different alleles (Table 1) and were optimized to be used simultaneously.

The extension reactions were performed in a final volume of $10 \mu \mathrm{l}$, containing $4 \mu \mathrm{l}$ of the PCR product purified with EXOSAP-It enzyme mix (USB Corporation, Cleveland, $\mathrm{OH}$ ), $5 \mu \mathrm{l}$ of the SNaPshot mix and 1.2 $\mu l$ of pooled primers (final concentrations: $0.24 \mu M$ of primers E4R166, E4R328, E4F328, and $0.12 \mu M$ of other primers). Thermal cycling consisted in 25 cycles of $10 \mathrm{~s}$ at $96^{\circ} \mathrm{C}, 5 \mathrm{~s}$ at $50^{\circ} \mathrm{C}$ and $30 \mathrm{~s}$ at $60^{\circ} \mathrm{C}$. To remove unincorporated ddNTPs, 1 unit of alkaline phosphatase (Roche Molecular Diagnosys) was added to the reaction mixture and incubated at $37^{\circ} \mathrm{C}$ for $1 \mathrm{~h}$ followed by a denaturation step at $72^{\circ} \mathrm{C}$ for $15 \mathrm{~min}$. One microliter of the extension reaction was mixed with $25 \mu$ l of formamide and analyzed by capillary electrophoresis and fluorescent detection using a Genetic Analyzer ABI 3100 and the accompanying Genescan software (PE Biosystems).

\section{Genotyping by PCR-Restriction Fragment Length Polymorphism}

All animal samples were also genotyped by the PCRRFLP method. Ten microliters of the PCR product (exon 4) were digested with 10 units of the restriction endonucleases Alw44I and HaeIII (Roche Molecular Diagnosys) overnight at $37^{\circ} \mathrm{C}$, and with $B s e \mathrm{NI}$ (Fermentas, Hanover, MD) at $65^{\circ} \mathrm{C}$ for $6 \mathrm{~h}$. The resultant fragments were separated by electrophoresis in a $2 \%$ agarose gel stained with ethidium bromide. 
Table 1. Primers used in the extension analysis.

\begin{tabular}{llll}
\hline Primer $^{1}$ & $\begin{array}{l}\text { Position } \\
\text { (exon } 4)\end{array}$ & $\begin{array}{l}\text { Size } \\
(\mathrm{bp})\end{array}$ & Sequence $\left(5^{\prime}-3^{\prime}\right)$ \\
\hline E4F-104 & 104 & 44 & (AT) $)_{5}$ AGTAGGTATCCTAGTTATGGACTCAATTACTATC \\
E4R-166 & 166 & 40 & (AT) $)_{9}$ AGGGCAGGTGACCTAACTGCAA \\
E4F-242 & 242 & 36 & (AT) $)_{8}$ ACCTGCCAAGTCCTGCCAAG \\
E4R-328 & 328 & 23 & AGCAATGGTATTGATGGCAGGGA \\
E4F-440 & 440 & 48 & (AT) $)_{13}$ GAAGCTTCCTCAGAATCGATTG \\
E4R-448 & 448 & 28 & ATAGTAACTTGGGCTGTGTTGGTCTCAG \\
\hline
\end{tabular}

${ }^{1} \mathrm{~F}$ : Forward, R: Reverse.

\section{RESULTS}

\section{Nucleotide Sequence Analysis of the $\kappa$-CN Full Coding Region}

We have previously detected four variants of the $\kappa$ $\mathrm{CN}$ gene by screening the major part of the coding sequences for mature protein (Yahyaoui et al., 2001; Angiolillo et al., 2002). In order to investigate whether the characterized variants are associated with other mutations in the remaining coding region, a total of $16 \mathrm{DNA}$ samples from different breeds were directly sequenced for exons 3 and 4. Among them, nine samples were previously genotyped and correspond to the alleles A, $\mathrm{B}$, and C. Sequence analysis of exon 3 (33 bp from which 27 are coding for mature protein) revealed a single nucleotide substitution (A to $\mathrm{G}$ ) at position 27 (from the start of the exon) in three samples from Murciana-Granadina and Girgentana breeds. This mutation is located at the third base of the codon Gln and therefore does not produce any amino acidic change.

The obtained sequences for exon 4 showed no additional mutations to those previously described. However, the existence of new haplotypes was suggested. For instance, some samples were heterozygotes $\mathrm{A} / \mathrm{G}$ at position 166 and homozygotes $\mathrm{C} / \mathrm{C}$ at position 448 (Table 2), indicating a new G-166/C-448 haplotype.

\section{Molecular Characterization of the New $\kappa-\mathrm{CN}$ Variants}

To ascertain these new haplotypes, PCR products were generated using a high fidelity Taq DNA polymerase and cloned into plasmid vectors. Two independent clones per sample were sequenced. Table 2 shows the two new $\kappa$-CN variants and corresponding amino acid differences deduced from the sequence analysis. The two novel haplotypes were designated $\kappa$-CN F and $\kappa$-CN $\mathrm{G}$ according to their order of detection. The difference between $\mathrm{F}$ and $\mathrm{G}$ variants involves only one amino acid substitution (valine for isoleucine) at position 65 of the $\kappa$-CN protein. The $\mathrm{F}$ variant presents valine and proline at positions 65 and 159 respectively, and this combination has not been observed in the previously reported goat variants. Conversely, this variant is identical to the exon 4 sequence obtained from the Spanish wild goat Capra pyrenaica. The $\mathrm{G}$ allele differs from $\mathrm{C}$ and $\mathrm{D}$ alleles by only one amino acid change at positions 440 (Ala/Val) and 104 (Gln/Arg), respectively.

\section{Genotyping and Allelic Frequencies of the $\kappa$-CN Variants}

Using PCR-RFLP for the endonucleases Alw44I, $B s e \mathrm{NI}$, and HaeIII, we have reported the frequency of

Table 2. Variants of the caprine $\kappa$-CN gene. Nucleotides present at polymorphic positions and corresponding amino acid changes (in parentheses) in each variant are indicated. Positions of nucleotides are relative to the start of exon 4. Amino acid positions in the protein are also indicated. The nucleotide sequences of the different $\kappa$-CN variants were deposited to GenBank under the accession numbers AF485339, AF485340, AF485341, AY090465, AF486523, AY090466, and AY090467.

\begin{tabular}{llllllllll}
\hline \multirow{2}{*}{$\begin{array}{l}\text { Position } \\
\text { (Exon 4) }\end{array}$} & $\begin{array}{c}\text { Position } \\
\text { (Protein) }\end{array}$ & A & B & C & D & E & F & G & Genotyping \\
\hline 104 & 44 & A (Gln) & A (Gln) & A (Gln) & G (Arg) & A (Gln) & A (Gln) & A (Gln) & \\
166 & 65 & G (Val) & G (Val) & A (Ile) & A (Ile) & G (Val) & G (Val) & A (Ile) & BseNI \\
242 & 90 & A (Asp) & A (Asp) & A (Asp) & A (Asp) & G (Gly) & A (Asp) & A (Asp) & Hae III \\
328 & 119 & G (Val) & A (Ile) & A (Ile) & A (lle) & A (Ile) & A (Ile) & A (Ile) & \\
440 & 156 & C (Ala) & C (Ala) & T (Val) & C (Ala) & C (Ala) & C (Ala) & C (Ala) & \\
448 & 159 & T (Ser) & T (Ser) & C (Pro) & C (Pro) & T (Ser) & C (Pro) & C (Pro) & Alw 44I \\
\hline
\end{tabular}

${ }^{1}$ Restriction enzymes used for PCR-RFLP genotyping. 
Table 3. Frequencies of the $\kappa$-CN variants in different European goat breeds.

\begin{tabular}{lllllllll}
\hline & & \multicolumn{7}{c}{ Variants } \\
\cline { 3 - 8 } Breeds & $\begin{array}{l}\text { No. of } \\
\text { animals }\end{array}$ & $\mathrm{A}$ & $\mathrm{B}$ & $\mathrm{C}$ & $\mathrm{D}$ & $\mathrm{E}$ & $\mathrm{F}$ & $\mathrm{G}$ \\
\hline Murciano-Granadina & 30 & 0.37 & 0.63 & - & - & - & - & - \\
Malagueña & 11 & 0.45 & 0.55 & - & - & - & - & - \\
Canaria & 30 & 0.58 & 0.42 & - & - & - & - & - \\
Teramana & 28 & - & 0.70 & 0.02 & 0.10 & - & 0.14 & 0.04 \\
Montefalcone & 17 & - & 0.59 & - & - & 0.41 & - & - \\
Girgentana & 19 & 0.34 & 0.45 & - & 0.05 & - & 0.05 & 0.11 \\
Sarda & 19 & 0.31 & 0.61 & - & - & - & 0.08 & - \\
Alpine & 28 & 0.34 & 0.66 & - & - & - & - & - \\
Saanen & 28 & 0.39 & 0.48 & 0.13 & - & - & - & - \\
Wild goat & 23 & - & 0.02 & - & - & - & 0.98 & - \\
\hline
\end{tabular}

the $\mathrm{C}$ and $\mathrm{E}$ alleles in different European goat breeds (Yahyaoui et al., 2001; Angiolillo et al., 2002). Samples indicated in Table 3 were also genotyped by this method, however, these endonucleases do not discriminate between alleles $\mathrm{A}$ and $\mathrm{B}$ or between $\mathrm{C}$ and the new allele $\mathrm{G}$ (Table 2). The primer extension analysis (PEA) allows genotyping of known SNP alleles by using appropriate primers and fluorescent detection. We have developed a set of primers that allow determination of the different goat $\kappa$-CN alleles (Figure 1). All samples were evaluated with this method using the six primers simultaneously. However, alleles A, C, D, and E can be individually differentiated from others by single genotyping using PEA-328, PEA-440, PEA-104, and PEA242 , respectively. Allele E can also be distinguished by PCR-RFLP with HaeIII endonuclease because this allele is the only one with guanine (Gly) at position 242 . Using the same technique, the $B s e \mathrm{NI}$ allows discrimination of alleles A, B, E, and F from others, whereas Alw44I distinguishes only A, B, and E alleles. Consequently, the $\mathrm{F}$ allele can be differentiated combining these two endonucleases. Table 3 shows the frequencies of the different $\kappa$-CN genetic variants in nine European goat breeds. The novel variants $\mathrm{F}$ and $\mathrm{G}$ are found only in the Italian breeds Teramana, Girgentana and Sarda, with a relatively high frequency. On the contrary, the $\mathrm{F}$ variant was the most frequent allele in the wild goat Capra pyrenaica. $\kappa$-CN A and B are the most common variants in the majority of breeds with a high prevalence of the B variant. An exception is the Canaria breed, where variant $\mathrm{A}$ is the most frequent ( $0.6 \mathrm{vs}$. $0.4) . \kappa-\mathrm{CN} B$ is the unique variant found in all analyzed breeds with frequencies ranging from 0.4 (Canaria) to 0.7 (Teramana). The $\mathrm{C}$ variant is present in Saanen (13\%) and the E variant is specific of Italian Montefalcone breed. The $\mathrm{D}$ variant is not found in the analyzed breeds, except in Teramana and Girgentana and at low frequencies (5 to 10\%).

\section{DISCUSSION}

This study describes the polymorphism of the caprine $\kappa$-CN gene. The full coding region which encompasses exons 3 and 4 was screened for polymorphisms by DNA

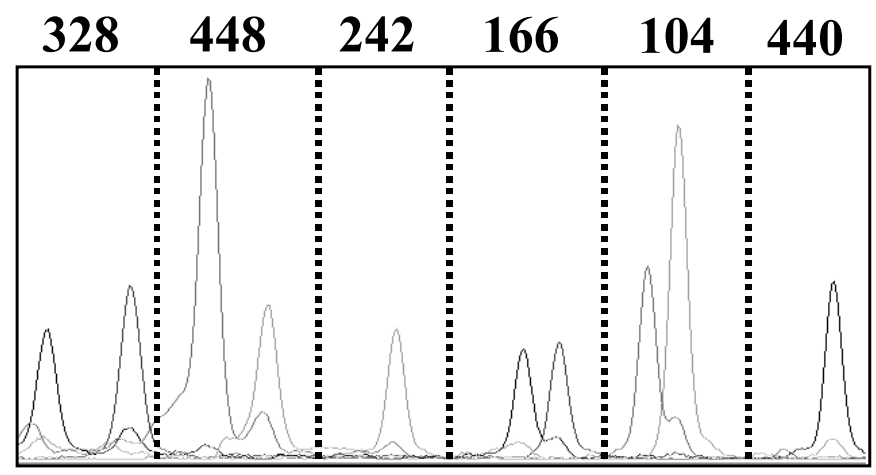

(a)

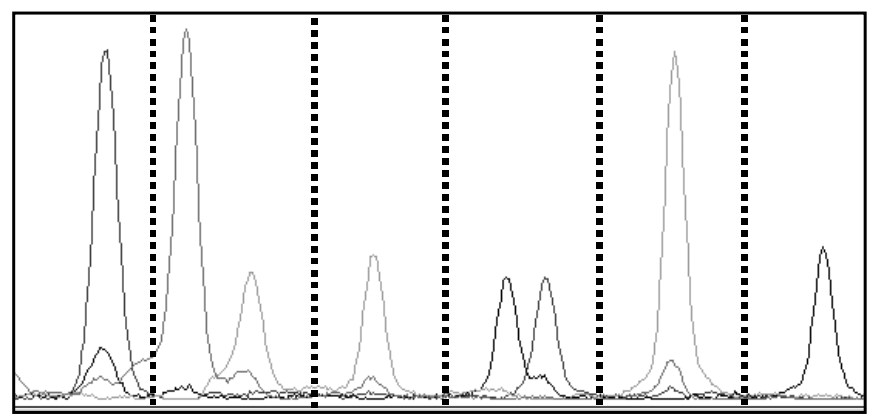

(b)

Figure 1. Genotyping of the $\kappa$-CN variants by primer extension analysis. The six mutations were analyzed simultaneously using primers shown in Table 1 . The six positions relative to exon 4 are indicated below. Shown genotypes are $\mathrm{AD}, \mathrm{BG}$ in a, b, respectively. Allele discrimination is based on both primer size and color (not shown in the figure) assigned to the fluorescent ddNTPs incorporated in the extension reaction. 


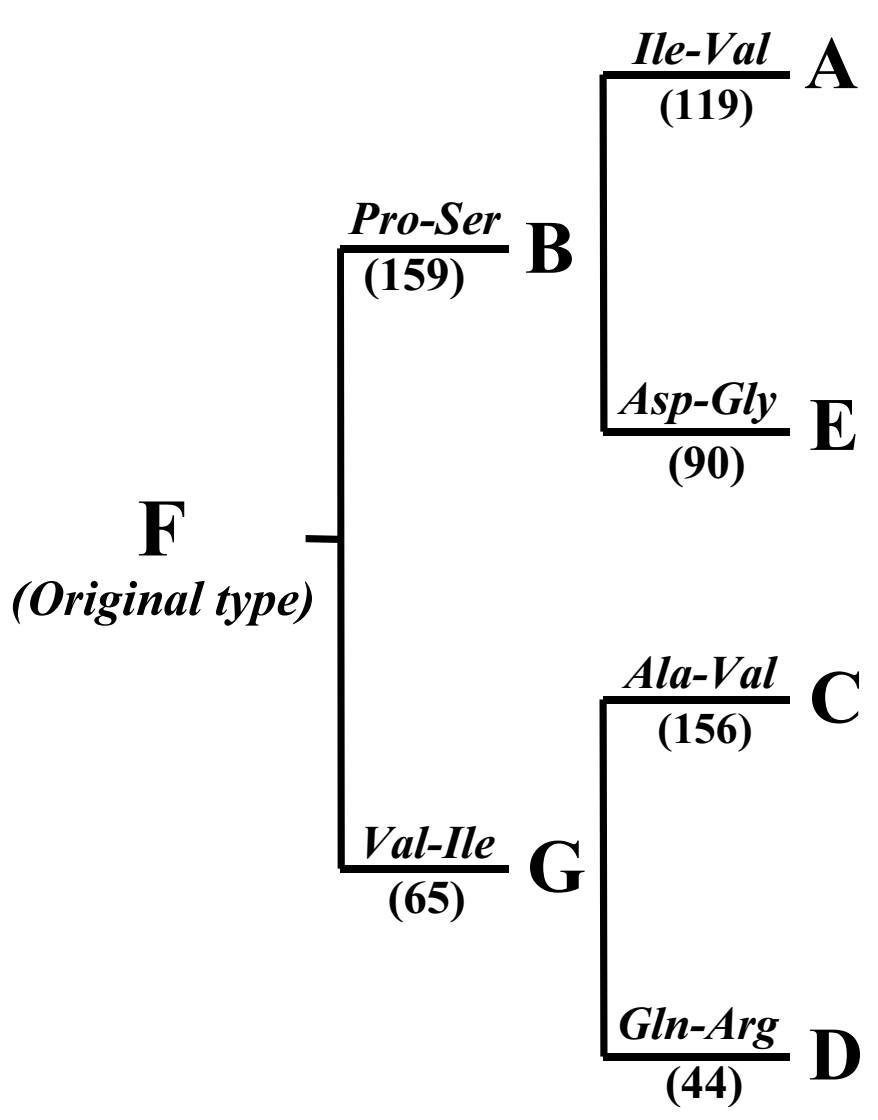

Figure 2. Proposed phylogenetic tree of the goat $\kappa-\mathrm{CN}$ variants. Amino acid changes and their position (in parentheses) are indicated.

sequencing. Although no mutations except those previously reported were detected, two new genetic variants resulting from the association between the different mutations are observed. To avoid the confusion now present in nomenclature, we suggest that caprine $\kappa$ $\mathrm{CN}$ variants would be designated according to the order in which they were reported: A, B, C (Yahyaoui et al., 2001), D (Caroli et al., 2001), E (Angiolillo et al., 2002), $\mathrm{F}$ and $\mathrm{G}$ (described in this paper). The new variants $\mathrm{F}$ and $\mathrm{G}$ are found only in the Italian breeds (Teramana, Sarda, and Girgentana) at frequencies ranging from 0.04 to 0.14 . Among the seven genetic variants characterized, only the B variant was found in all studied populations and is predominant over other alleles, except in Spanish Canaria breed. It could therefore be considered as the original variant on the basis of frequency criterion; the original variant is expected to have the highest frequency over a large number of populations. However, when considering comparative sequence data, variant $\mathrm{F}$ is identical at position 159 to the $\kappa$-CN of other species (sheep, cattle, pig, mouse, rat, rabbit, camel and human), all having proline, while the $B$ variant presents serine at this position. In addition, the $\mathrm{F}$ variant is identical to the sequence of the $\kappa$-CN exon 4 obtained from the Spanish wild goat. The similarity of sequences indicates that this variant is likely the original type. The reasons of the divergence in the conclusions of the frequency and of the sequence conservation criteria are unclear. Because the $\kappa$ - $\mathrm{CN}$ plays a critical role in several important physiological processes, it seems unlikely that this gene would be completely free of the selective pressure, and there is evidence for positive selection within the family Bovidae (Ward et al., 1997). Thus, the low frequency of variant $\mathrm{F}$ could have come through selection, and it was supplanted very early by type B. In this regard, it is important to notice that the chemical and nutritional properties of the amino acid residues serine and proline (in $\mathrm{F}$ and $\mathrm{B}$ variants, respectively) are very different. However, genetic drift and founder effect could also explain the prevalence of the B variant. Until further developments by typing more goat populations, either of wild type or goat breeds and especially non-European breeds, the $\mathrm{F}$ variant could be considered as the ancestral type. The different alleles were most likely derived from this original type by successive mutations following two distinct trunks (Figure 2): A, B, and E, which occur, when found, at high frequencies; and C, D, and $\mathrm{G}$ which are observed at low frequencies.

In goats, the three calcium-sensitive casein genes $(\alpha \mathrm{s} 1, \alpha \mathrm{s} 2$, and $\beta)$ are polymorphic and alleles are associated with strong differences in their level of expression. Alleles with a null amount of protein have been found for the three genes. In this regard, the high level of genetic variability observed at the casein loci and its association with milk traits allows groups of animals producing types of milk which could be more suitable for specific technologies of transformation or for specific needs of human nutrition to be obtained (Rando et al., 2000). Due to the linkage between casein genes it is necessary to take into account $\kappa$-CN when considering haplotype studies in order to include milk protein variants in breeding programmes. The technique described here allows the rapid and simultaneous genotyping of all known $\kappa$-CN variants, and because an automated instrument was used, it was suitable for large screening and genotyping in selection schemes and industrial purposes.

Further studies involving different goat breeds are required to elucidate whether these $\kappa$-CN polymorphisms have a physiological role, as observed in bovine, and to identify their linkage within the casein cluster.

\section{ACKNOWLEDGMENTS}

We would like to thank the Agencia Española de Cooperación Internacional (AECI) for the research 
scholarship of M.H.Y. This research was partially funded by Cofin MIUR 2001.

\section{REFERENCES}

Angiolillo, A., M. H. Yahyaoui, A. Sanchez, F. Pilla, and J. M. Folch. 2002. Characterization of a new genetic variant in the caprine $\kappa$-casein gene. J. Dairy Sci. 85:2679-2680.

Ausubel, F. M., R. Brent, R. E. Kingston, D. D. Moore, G. G. Seidman, J. A. Smith, and K. Struhl (Eds). 1987. Current protocols in molecular biology. Green Publishing Associates and Wiley-Interscience, New York, NY.

Boland, M., A. MacGibbon, and J. Hill. 2001. Designer milks for the new millenium. Livest. Prod. Sci. 72:99-109.

Caroli, A., O. Jann, E. Budelli, P. Bolla, S. Jäger, and G. Erhardt. 2001. Genetic polymorphism of goat $\kappa$-casein in different breeds and characterization at DNA level. Ani. Gen. 32:226-230.

Coll, A., J. M. Folch, and A. Sanchez. 1993. Nucleotide sequence of the goat $\kappa$-casein cDNA. J. Anim. Sci. 71:2833

Coll, A., J. M. Folch, and A. Sanchez. 1995. Structural features of the $5^{\prime}$ flanking region of the caprine $\kappa$-casein gene. J. Dairy Sci. 78:973-977.

Corpet, F. 1988. Multiple sequence alignment with hierarchical clustering. Nucl. Acids Res. 16:10881-10890.

Gutierrez, A., E. A. Maga, H. Meade, C. F. Shoemaker, J. F. Medrano, G. B. Anderson, and J. D. Murray. 1996. Alterations of the physi- cal characteristics of milk from transgenic mice producing bovine $\kappa$-casein. J. Dairy Sci. 79:791-799.

Kaminski, S. 1996. Bovine $\kappa$-casein gene: molecular nature and application in dairy cattle breeding. J. Appl. Gen. 37:176-196.

Mercier, J. C., F. Addeo, and J. P. Pelissier. 1976a. Structure primaire du caséinomacropeptide de la caséine kappa caprine. Biochimie 58:1303-1310.

Mercier, J. C., J. M. Chobert, and F. Addeo. 1976b. Comparative study of the amino acid sequences of the caseinomacropeptides from seven species. FEBS Letters 72:208-214.

Moioli, B., F. Pilla, and C. Tripaldi. 1998. Detection of milk protein genetic polymorphisms in order to improve dairy traits in sheep and goats: a review. Small Rum. Res. 27:185-195.

Ng-Kwai-Hang, K. F. 1998. Genetic polymorphism of milk proteins: relationships with production traits, milk composition and technological properties. Can. J. Anim. Sci. 78 (Suppl):131-147.

Rando, A., L. Ramuno, and P. Masina. 2000. Mutations in casein genes. Zoot. Nutr. Anim. 26:105-114.

Schaar, J. 1984. Effect of $\kappa$-casein genetic variants and lactation number on the renneting properties of individual milks. J. Dairy Res. 51:397-406.

Ward T. J., R. L. Honeucutt, and J. N. Derr. 1997. Nucleotide sequence evolution at the $\kappa$-casein locus: evidence for positive selection within the family bovidae. Genetics 147:1863-1872.

Yahyaoui, M. H., A. Coll, A. Sanchez, and J. M. Folch. 2001. Genetic polymorphism of the caprine kappa casein gene. J. Dairy Res. 68:209-216. 